\title{
The Development of a Subject Classification Scheme for the Bibliography of Canadian Science and Technology to 1914
}

\author{
Bertrum H. MacDonald and R. Alan Richardson
}

Bibliography as an activity has existed for some time. ${ }^{1}$ There are, however, different views of how the term may be defined. For example, the wellknown figure in bibliographic work, Sir Walter Greg, wrote that 'bibliography has nothing whatever to do with the subject or literary content of the book. ${ }^{2}$ While certain scholars, such as Roy Stokes, still espouse this view, ${ }^{3}$ it can be strongly argued that at least some branches of bibliography have everything to do with the subject of the works under consideration. Subject bibliography has figured prominently in national and international conferences on bibliography ${ }^{4}$ and, indeed, because of the very real demand for subject bibliographies such tools arranged according to some subject order continue to be prepared. ${ }^{5}$

It was the call for just such a bibliographic device that gave rise to the Bibliography of Canadian Science and Technology to 1914, a bibliography currently in preparation and funded by research grants from the Social Sciences and Humanities Research Council of Canada. The history of science, and bibliography in the field, can trace their roots at least into the last century. ${ }^{6}$ There are, however, design problems unique to a retrospective bibliography of science. Prominent here is the lack of a subject classification appropriate for all bibliographies of science and technology. For the purposes of this discussion, technology can be considered 'applied science.' A subject classification scheme that could be adopted in its entirety for the Bibliography of Canadian Science and Technology to 1914 could not be found, and since other schemes required considerable modification before they could be used, the decision was made to build our own, drawing on a large number of sources and considerable expertise.

In the present paper we discuss the methodology applied and difficulties encountered, and make observations about the development and use of the subject classification. The construction of a subject classification scheme involves theoretical and practical decisions, both of which will be discussed.

An earlier version of this paper was presented to the Bibliographical Society of Canada at its Annual Meeting in Calgary, I 2 June 1985. 
Two points need to be stated at the outset. First, in case there may be any doubt, bibliography is viewed here from the enumerative point of view. The rather straight-forward definition - a bibliography is a tool designed to 'assist an enquirer in discovering the existence or determining the identity of books or other documentary material which may be of interest to him ${ }^{7}$ is employed. Second, the subject classification and associated thesaurus are not yet fixed. They will remain dynamic throughout the period of the preparation of the bibliography although in their current state they have largely reached their expected final form.

\section{The Bibliography}

A brief description of the bibliography, which has been discussed in more detail elsewhere, ${ }^{8}$ will be useful here. It is a large bibliographic project and will, upon its completion in late I986, have accumulated an estimated 60,000 records. The entries represent published primary works dealing with science, engineering, and technology. Secondary works, such as biographies and historical discussions of institutions and manufacturing firms are being excluded. Although most of the entries come from periodical sources, an estimated Io,000 entries arise from monographs. Entries are created for primary works published in Canada or abroad written in English, French, or other languages - with the vast majority being in English.

A number of definitions had to be built into the design of the bibliography from the beginning. For as Ingles and Montague have noted, 'the creators of most retrospective bibliography projects, while often originally committed to the idea of inclusivity, have usually been obliged to settle for a more practical definition of the material they recorded. ${ }^{\prime 9}$ First, this bibliography is limited to works about Canada. Canadian science and technology is defined as any scientific or technological work published in or outside Canada by a Canadian, or published in Canada or abroad by a non-Canadian if the work contains some substantial material about Canada. Canada is taken to mean the country circumscribed by the current national boundaries. For the most part this definition of Canadian follows that adopted by the National Library of Canada for Canadiana 1867-1900 Monographs and by the Canadian Institute for Historical Microreproductions (СінM) for Canada the Printed Record. ${ }^{10}$ However, an entry is not prepared for a work with a Canadian imprint unless the work itself contains some substantial material about science and technology in Canada, or was written by a Canadian.

The second definition that was considered for this bibliography was the time parameters. While there is no precise beginning date (except of course, the date of the earliest document that will be included in the bibliography), the definitive cut-off date is the end of I9I3. Most of the entries represent 
works of post-I 850 imprint, but the publication period spans three or more centuries.

A third definition that required clarification at the beginning of the project was the identification of the prospective users of the bibliography. The assumption was made that the majority of the users would be historians, particularly historians of science and technology. In addition, it was envisaged that sociologists, analysts of science policy, bibliographers, and information scientists might find the bibliography of benefit.

All of the above definitions, plus some less important questions, had an impact on the decision regarding a major element of the design of the bibliography, namely how to define science and technology. The remainder of this paper is devoted to a discussion of the outcome of the solutions adopted.

\section{Development of the Subject Classification and Thesaurus}

Subject access to the bibliography was a necessary priority. Author and title access alone would not be sufficient, for as A.C. Foskett has written, 'readers are interested in documents for what they contain. ${ }^{11}$ However, the decision to provide subject access led to a number of difficulties:

I. To our knowledge no other country has undertaken a project similar to the one described here, and, as a result, a design model was not available to either adopt or adapt.

2. Bibliographies for the history of science and technology exist and in some cases their classified design has been described. ${ }^{12}$ These bibliographies are mainly concerned with secondary works, and their classified structures are not suitable for primary works because they do not provide the level of detail required for this study.

3. The design of the subject classification was complicated by the fact that the bibliography includes entries for works published over three centuries during which science and its terminology underwent dramatic development. And further, those using the bibliography will approach it with a late twentieth-century view of what constitutes science and technology, or what constitutes the various disciplines within science and technology.

The decision was made to develop a subject classification scheme according to these criteria and the results are documented here. First we will describe the methodology adopted for its construction and in so doing discuss aspects of the scheme, then we will present a number of observations.

\section{Methodology}

Experience with a pilot project demonstrated that a broad interpretation of science and technology would be appropriate. ${ }^{13}$ Such an interpretation means, for example, that entries for geographical works are included since 
very often they contain descriptions of the natural history of an area or note topographic or cartographic data. Medical works, except those that treat the topic primarily from the point of view of anatomy or physiology (i.e., more strictly science), are excluded. ${ }^{14}$

In the construction of the subject classification scheme, factors other than the broad definition of science and technology came into play, including:

I. The subject classification is to serve two purposes, namely, a structure for one section of the final product, and, a mechanism for consistent subject assignment by a single individual or among research assistants who would be scanning the actual works and assigning subject keys.

2. The subject classification was designed to be used in the field and, therefore, was, for the most part, built prior to any actual bibliographic transcription work. Since it was not possible to predict accurately the number of entries for any particular subject, it was decided that rather narrow subject categories should be used initially, while the possibility of collapsing categories at later stages of the project if necessary was retained. Of course the opposite situation might occur, i.e., a descriptor might be too broad and, therefore, make access too cumbersome because of the high number of entries assigned to it. An attempt was made to prevent the occurrence of overly broad categories, since at the final editing stages of the bibliography it might be very difficult to assign narrower categories when only the bibliographic record and not the actual work is available. Accordingly, over I60 major and minor divisions have been established.

3. A subject descriptor was taken to mean a term or string of terms that would describe the entire contents of a work. This differs, of course, from indexing (which we deliberately intended not to do, due to the size of the database and the time and funds allocated to the project) in which the index entries specify only a portion or maybe a theme of a work.

The subject classification was built in several stages and employed a combination of methodologies. ${ }^{15}$ Two basic methods for designing indexing languages, particularly thesauri, have been employed: the 'empirical' approach in which the candidate terms or headings are extracted from the literature, and the 'committee' approach in which the headings or descriptors are selected by a panel of appropriate subject experts. While there are proponents of both procedures, Kim and Kim have shown that one strategy is not better than the other. ${ }^{16}$ A combination of both methodologies was adopted here. The system, while largely generated from literary warrant, ${ }^{17}$ also drew on the knowledge of subject experts. A means of clearly defining the subject categories was necessary especially for use by staff members. A method was devised that involved assigning terms to each heading, terms that might be found in the literature that would be scanned. This method 
was deemed more helpful than providing definitions alone.

With this structure in view - a subject classification and what may be broadly called a thesaurus of terms - a number of late nineteenth- and early twentieth-century sources were consulted from which over 2,000 terms or headings were extracted. ${ }^{18}$ Then, by using knowledge gained from the pilot project and by consulting several other published works, ${ }^{19}$ the subject categories were established and an overall structure adopted for the list. The categories were first split into scientific and technological topics and then within these two groupings categories were arranged alphabetically according to major divisions. Subdivisions of a major category follow the major category in alphabetical order (see Appendices A and B which give sample extracts from both the scientific and technological topics), or in a few cases in 'logical' order (see the Mining category and its subdivisions in Appendix B). Once the overall structure of the scheme had been established, the 2,000 or more terms were assigned to their appropriate categories and arranged alphabetically under the category. Finally, an inverted index of all the terms was prepared and sorted in alphabetical order (see a section of the inverted index in Appendix c). All three sections of the subject classification scheme (Outline of the Subject Categories, Thesaurus, and Inverted Index) were entered into computer files for ease of revision.

After the initial subject classification scheme was completed, it was tested by using it for subject analysis of two periodicals - a science journal and a technology journal. This procedure helped to identify weaknesses in the structure and revisions were carried out. The mining category, for example, which originally was created as a single category without subdivisions, immediately posed some difficulty. In transcribing records from the technology periodical it was quickly realized that the heading should be subdivided to handle the large number of records that would be encountered. At this point the assistance of subject experts was sought and modifications were made in keeping with their advice. ${ }^{20}$ This revised subject classification scheme was used throughout the first data collection phase, during which about 25,000 records were obtained. As the system was being used revisions continued to be made as necessary. Some of the revisions included:

I. Categories were added, e.g., a category for 'Industrial Machinery and Components.'

2. Terms in existing descriptors were revised to more appropriately reflect the subject of the category, e.g., 'Agricultural Chemistry' was changed to 'Agricultural Chemistry and Soils.'

3. Definitions of existing categories were clarified, e.g., the subordinate categories, 'Palaeobotany' and 'Palaeozoology' were used when a work deals solely with one or the other topic; if both topics are discussed in the same work the broader category, 'Palaeontology' is used. 
Further refinements in the development of the subject classification scheme were introduced at the end of the first phase of data collection which included:

r. Five categories embedded in the scientific section /archives, education, exhibitions, museums, and societies) were removed to create a third section of categories called, General Topics, placed at the beginning of the subject classification scheme. It had been found that entries assigned to these categories, such as education, included works dealing with science and technology and, therefore, needed to be set apart from the scientific topics.

2. Every term in the thesaurus was checked to determine that it was in the right location. A number of errors were found and corrected.

3. A few categories were revised. The 'Energy' category received major revisions to account for the large number of works on electricity that were found. 'Electricity' was made a part of the 'Energy' category and five subdivisions were added.

4. Every subject descriptor in the complete scheme was rechecked to ascertain whether the terms in the categories were appropriate.

5. A new category was created, called 'Study of Inland Waters (including Limnology).'

6. Several additional published sources were checked for other possible terms, and new terms were added to the thesaurus. ${ }^{21}$

7. Definitions were added to categories in the thesaurus that needed clarification, e.g., 'Biochemistry,' 'Organic Chemistry,' 'Geodesy,' 'Geophysics and Physical Geology,' and others (see Appendix D for the definition included with the descriptor 'Geophysics and Physical Geology').

8. Numerous scope notes were added to the thesaurus to clarify terms or descriptors, e.g., the notes for 'Natural History,' 'Pathology,' 'Hydro Power (not Electrical), Windmills,' and 'Electricity' (see Appendix E for the scope note included with the 'Electricity' descriptor).

9. Numerous see also references were added to refer the user to related categories (see examples in Appendices D and E).

The system continues to be dynamic and will remain so until the bibliography is complete. Major revisions are not expected. Until the bibliography is completed new terms encountered in the literature may be added to the thesaurus if needed.

\section{Comments on the Subject Classification Scheme}

Having outlined how the subject classification scheme was built, a few comments can be made about it - first one or two specific points, then more general observations. 


\section{PROBLEMS AND DECISIONS}

I. One of the major difficulties in devising a subject classification for a bibliography of this type is the long time span that the literature covers, and the distance between present-day users of the bibliography and the world view of those who wrote the works that are covered in it. Almost a century and a half ago, J.W. Lubbock wrote that 'any system of classification of the branches of Human knowledge which may be proposed can only have reference to the state of civilization at some particular epoch. ${ }^{22}$ What was science or technology to a seventeenth-century writer could be vastly different to a nineteenth- or twentieth-century author. Growth in the sciences throughout the nineteenth century (most of the entries in the bibliography are from the nineteenth century) was rapid and can be measured in a number of ways. The most notable transformation was in the increased specialization that occurred. In the early years of the I80os many scientists were generalists - natural historians, for example. By I900 natural history had been replaced by botany, zoology, physiology, entomology, and microbiology. ${ }^{23}$ Even within these fields, research had been further compartmentalized. As an illustration, an individual working in entomology could investigate aspects of the subject which dealt primarily with taxonomy, physiology, or economic entomology, a study of those insects affecting agriculture.

To choose a period from which a subject classification could be drawn, therefore, posed a problem. We decided to model the view of science at about I900 assuming that science and technology at this time could accommodate the literature to be documented. But, as might be expected, compromises had to be made. For example, although natural history had by I900 developed into specialized fields (and those specialized fields appear in the subject classification) it was still not possible to eliminate a heading for natural history because early works on the topic could not be assigned to one or more of the specialized fields that had developed.

Additional compromises were necessary. The first department of biochemistry in Canada was created in I908. ${ }^{24}$ The term biochemistry gained prominence at that time although biochemical research had occurred for a number of decades prior to I 908 when it was more often called physiological chemistry or cellular chemistry. Since the latter descriptors had gone out of use and probably would not be understood by late twentieth-century users of this bibliography, the descriptor 'Biochemistry' was chosen, recognizing, of course, that this is imposing a later concept on nineteenth-century work.

2. A concern for arrangement became primary once the subject headings had been established. ${ }^{25}$ A number of arrangements could have been adopted. George Richardson, a historian of mining and technology, for example, suggested we divide the time period covered by the bibliography and devise a 
classification scheme for each period. ${ }^{26}$ This sort of arrangement might be suitable if the history of science and technology in Canada was a wellestablished field and historians treated the subject in this manner. But this is not yet the case. Further, to impose such a structure on the bibliography in advance of examining the literature would be difficult. And, finally, such divisions would confuse the user of the bibliography if different descriptors were used in each time period.

Assuming that most users will be historians, a major division of the categories into scientific topics, technological topics, and those that overlap both was adopted, largely because historians are split into two groups those that deal with science and those that treat technology. Within each of the three topics major categories are listed alphabetically. While in some senses this arrangement is partially alphabetico-classified (subdivisions of a major category follow that category) the order of the list is largely alphabetical. To develop a fully classified list would require extensive research and would run the risk of collocating categories that for one time period may be appropriate and for others not. The least amount of error occurs by adopting an alphabetical list and this arrangement does not prejudice how researchers may ultimately group items.

3. Assistance in construction of this subject scheme has been limited by the little historical assessment of the topic. Encouraging signs, such as the publication of Scientia Canadensis, a journal devoted to the history of Canadian science and technology, suggest that the future may see advances in historical studies. But for the moment it means that we have little guidance on how the works cited in the bibliography might be used from the point of view of specific subjects.

4. To a large extent the choice of terms for the subject descriptors has come from literary warrant. In addition, the terms in the thesaurus have largely come from the literature itself. Literary warrant is not always helpful for there may be a lack of terms to designate a concept. For example, the heading 'Study of Inland Waters (including Limnology),' is an artificial construction. A single term to describe this type of study does not exist. Numerous works dealt with this topic, but these could not be entered under 'Oceanography' since this subject is concerned with marine waters. Thus it was necessary to create a category and since it is a field of study similar to 'Oceanography' it appears next to 'Oceanography' and out of alphabetical order in the subject classification.

The choice of descriptors was carefully made to avoid any necessity of inverting terms to place a more significant term at the beginning of the heading. C.A. Cutter, an early advocate of systematized subject descriptors, declared that a compound subject descriptor should only be inverted 'when some other word is decidedly more significant or is often used alone with 
the same meaning as the whole name. ${ }^{27}$ But to determine the most significant word is not always an easy task. We, therefore, avoided the problem by choosing descriptors that did not require inversion. Our scheme is also partially classified and this helps to prevent the problem of inversion.

5. A few categories are probably, strictly speaking, not scientific or technological topics, e.g., 'Agricultural Economics.' Since works on this type of subject were encountered with some frequency in science or technology journals, it was thought unwise to leave them out.

6. The thesaurus of terms is not intended to be an exhaustive list. If a term encountered in the literature is not in the thesaurus, the research assistants can determine where it might appear by reviewing the existing descriptors and terms.

7. The thesaurus terms are occasionally assigned to more than one subject. For example, the term 'Coal' (see Appendix c) appears under the category 'Fuels' and also the category 'Mineralogy, Economic Geology, Crystallography.' Since a term can have different meanings or implications depending on the context, it is not possible to assign some terms to single subject categories. A user of the list may have to refer to the full group of terms under a category to grasp the meaning of the term in such cases. In effect, such a structure is polyhierarchical for such terms.

8. The subject classification scheme is designed as a precoordinate indexing language. The possibility of making the bibliography available on-line may change this somewhat, however. A precoordinate system requires extensive up-front work, a one-time investment in the conceptualization of the subject descriptors and their application.

9. A number of subjects are related to others in the list. See also references have been added. The process of adding cross references will continue as we gain an understanding of the literature. A subject-classed system, which this is, at least in part, requires fewer cross references than a strictly alphabetical system.

\section{GENERAL OBSERVATIONS}

Now that a number of specific problems and decisions have been documented, we can turn the discussion to a more general nature.

I. In an essay entitled, 'Historical Aspects of the Classification of Science,' B.C. Vickery amply demonstrates that over a period of several centuries scholars did not reach a concensus on how to classify the sciences. ${ }^{28}$ Even within short time spans there was no agreement on how science and technology should be compartmentalized, which led Vickery to comment that 'each new epoch requires a new classification. ${ }^{29}$ Further evidence that this problem in subject analysis of the sciences exists is seen in the difficulty encountered by the Royal Society of London in devising subject 
access to their work, The Catalogue of Scientific Papers 1800-1900. Subject access was never accomplished during the production of this major scientific bibliography. ${ }^{30}$ The conceptualization of the sciences remains a challenge $^{31}$ and, therefore, the steps and decisions followed in the preparation of the subject scheme for the Bibliography of Canadian Science and Technology to 1914 are not unusual.

2. The type of subject scheme adopted here does not provide an exact model of modern information retrieval systems. The categories and descriptors finally placed in the bibliography will remain 'frozen' and will not be modified as new terms or new meanings are generated. Dagobert Soergel has stated that 'a thesaurus is never complete. ${ }^{32}$ For this subject scheme, however, alterations will not take place after the bibliography is completed.

3. In creating this subject scheme it was not always clear whether the product was a list of subject headings, a classification scheme, or a means of indexing. In effect, the subject scheme described here combines features of all three.

4. A number of difficulties in employing this scheme remain. First, sometimes it is difficult to cope with the dichotomy of the scheme - is a work only science or only technology? Veterinary medicine is found in the technological topics. Some might argue that this subject is more correctly a science. Yet, historians of technology consider agriculture their domain and since veterinary medicine is part of this subject it is grouped with other agricultural topics. Second, with existing headings, scope-matching is not always accomplished. Francis Miksa defines scope-matching as a process 'by which the extent of the topical content of a document is matched by means of a subject heading, whether or not the actual heading accurately scopematches the work by some other more formal and exact measure. ${ }^{33}$ For example, a work on railway locomotives is entered under 'Transportation Railroad Engineering and Vehicles,' when it might have also been assigned to the 'Mechanical Technology' heading, 'Industrial Machinery and Components.' The attempt is made to enter such works under the most related heading but this may not be the best resolution of the difficulty.

5. The choice of descriptors, as already indicated, was sometimes made with difficulty. In a number of cases parenthetical qualifiers were added. For example, in 'Energy - Hydropower (not Electrical) and Windmills,' the parenthetical modifier was added to distinguish the heading from the electricity heading, 'Energy - Electricity - Power Generation, Storage, and 'Transmission.' Rules for the formation of subject categories have never been clearly articulated. One of the decisions that must be made is when to subdivide a subject category. There is no rule to provide guidance in this matter but a seemingly unwritten rule is that a category should be divided when the volume of entries under a single category becomes too bulky for a user. In 
such cases subdivision should be made to improve access. Accordingly, a number of levels (up to three) appear in some of the categories of the subject scheme. These decisions were made almost solely because of the volume of literature encountered in each case. Further subdivisions may be necessary as the data accumulates but this retroactive division may be difficult to carry out.

6. A decision has not yet been made whether the detailed subject scheme will be included in the introductory matter to the final copy of the bibliography. While the Outline of the Subject Classification will need to be included, the remainder of the subject scheme may also be helpful to a user. The scope notes added to the thesaurus, for example, were designed primarily for those assigning subject keys. They may also be of help to a user of the bibliography.

In conclusion, the arrangement of a large bibliography, such as ours, is, in the words of Lewin Robinson, 'of greatest importance, and the way in which it is done makes all the difference between a mere unwieldy list of titles and a useful and easily consulted reference tool. ${ }^{34}$ Subject access is significant in this regard. The design of the subject scheme for the Bibliography of Canadian Science and Technology to 1914 has required extensive research and endeavor since a ready-made subject scheme was not available. ${ }^{35}$ Ultimately, the effectiveness of the scheme described in this paper will be determined in its use, but this will only be known after the publication of the bibliography.

NOTES

We wish to thank the Social Sciences and Humanities Research Council of Canada for its financial support of this project under the Strategic Grants Programme, 'Canadian Studies: Research Tools.'

I The Oxford English Dictionary gives the date of the earliest use of the word as 1678 with a now obsolete definition of 'the writing of books.' See OED, James A.H. Murray, Henry Bradley, W.A. Craigie, and C.T. Onions, eds., s.v. 'bibliography.'

2 W.W. Greg, 'Bibliography - A Retrospect,' in The Bibliographical Society, The Bibliographical Society, 1892-1942, Studies in Retrospect (London: The Bibliographical Society, I945l, p. 24.

3 See Roy Stokes, The Function of Bibliography, 2d ed. (Aldershot, England: Gower Publishing Company Limited, I982), pp. 4-5.

4 See for example, Anne B. Piternick, ed., National Conference on the State of Canadian Bibliography. Vancouver, Canada. May 22-24, 1974. Proceedings (Ottawa: National Library of Canada, I977); and Elizabeth Hulse, ed., The Bibliographical Society of Canada, Colloquium III. National Library of Canada, Ottawa, 19-21 October 1978 (Toronto: Bibliographical Society of Canada, I979) both of which have major sections on subject bibliography.

5 Roy Stokes somewhat reluctantly admits this point. See Stokes, Function of Bibliography, p. I05. 
6 See for example, A.N.L. Munby, The History and Bibliography of Science in England: The First Phase, 1833-1845 (Berkeley \& Los Angeles: University of California, 1968).

7 A.M. Lewin Robinson, Systematic Bibliography (London: Clive Bingley, r979), p. I3.

8 The earliest paper describing the bibliography is Bertrum MacDonald, 'Science in Canada to the Twentieth Century: A Bibliography' (paper presented to the Canadian Society for the History and Philosophy of Science, Learned Societies meeting, Fredericton, May 1977). A more recent paper which outlines the design of the current project is Bertrum H. MacDonald and R. Alan Richardson, 'Science and Technology in Canadian History: A Report on the Construction of the Retrospective Bibliography' (paper presented to the Association for the Bibliography of History, San Francisco, December 1983).

9 Ernest B. Ingles and Robert Montague, 'The Canadian Institute for Historical Microreproductions: Objectives - Methodologies,' Canadian Issues 4 (I982): I40.

Io See Canadiana 1867-1900 Monographs, Canada's National Bibliography, Microfiche Edition (An Introduction) (Ottawa: National Library of Canada, 1980), pp. 7-Io; and Canada: The Printed Record. A Bibliographic Record with Indexes to the Microfiche Series of the Canadian Institute for Historical Microreproductions (Ottawa: Canadian Institute for Historical Microreproductions, I98I), \#2. Both the National Library and сінм interpret the term Canadian very broadly. We have followed the National Library motto, 'when in doubt, include.'

Canadiana 1867-1900, p. 7.

I I A.C. Foskett, 'E.J. Coates, The British Technology Index and the Theory of Subject Headings: The Man Who Loved Cat Springing,' in W. Boyd Rayward, ed., The Variety of Librarianship. Essays in Honour of John Wallace Metcalfe (Sydney: Library Association of Australia, 1976), p. 77.

I2 See for example, Magda Whitrow, 'Classification Schemes for the History of Science: A Comparison,' Journal of Documentation 20, no. 3 (I964): I 20-36, and her more recent paper 'Interrelationships in the History of Science: Bibliography as a Guide to Subjects for Research,' Isis 74, no. 27 I (I983): 8I-85. See also Jack Goodwin, 'Current Bibliography in the History of Technology (r98I),' Technology and Culture 24 (I983): 3 I6-98, especially pp. 3 I 8-I9.

I3 Bertrum H. MacDonald and R. Alan Richardson, Preliminary Bibliographical Inventory of Sources in the History of Science, Technology, and Medicine in Canada to the Twentieth Century (London: Department of History of Medicine and Science, University of Western Ontario, I98I), pp. xiv, 275, 335. This volume was published in limited edition and distributed to selected colleagues for review. Favorable comments were received. See for example, Raymond Duchesne, 'Historiographie des sciences et des téchniques au Canada,' Révue d'historie de l'Amérique français 35, no. 2 (September 1981): r96-97.

I4 A bibliography of Canadian medicine is being prepared by Dr. Charles Roland, Professor of the History of Medicine at McMaster University, Hamilton, Ontario.

I5 A number of manuals have been written on how to construct subject or indexing languages of which one of the more detailed is Dagobert Soergel, Indexing Languages and Thesauri: Construction and Maintenance (Los Angeles: Melville Publishing Company, 1974).

I6 Chai Kim and Soon D. Kim, 'Concensus Vs Frequency: An Empirical Investigation of the Theories for Identifying Descriptors in Designing Retrieval Thesauri,' Information Processing $\oiiint$ Management I3 (1977): 253-58.

I7 A.C. Foskett has noted that 'the term literary warrant is used ... to denote that ... [a] 
system must be based on the information we put into it rather than on purely theoretical considerations.' A.C. Foskett, The Subject Approach to Information, 4th ed. (London: Clive Bingley, r982), p. 3 I.

I 8 The works consulted for the initial design of the subject scheme included:

John Patterson, ed., Canadian Institute. General Index to Publications, 1852-1912

(Toronto: University Press, I9 I4).

Melvil Dewey, Decimal Classification and Relative Index for Libraries, Clippings, Notes, etc., 7 th ed. (New York: Forest Press, I9II).

Aksel G.S. Josephson, The John Crerar Library. A List of Books on the History of Industry and Industrial Arts (Chicago: Printed by the order of the Board of Directors, I915).

A Catalogue of British Scientific and Technical books (London: British Science Guild, I 92 I).

Aksel G.S. Josephson, The John Crerar Library. A List of Books on the History of Science, January 1911 (Chicago: Printed by the order of the Board of Directors, I9 I I; reprint ed., New York: Kraus Reprint Corporation, I966).

I9 The works consulted included the papers by Whitrow and Goodwin cited in note I 2 above, the works by Josephson cited in note $\mathrm{I} 8$ above and the following:

John Neu, 'The History of Science,' in Robert B. Downs and Frances B. Jenkins, eds., Bibliography Current State and Future Trends (Chicago: University of Illinois Press, 1962), pp. 438-54.

Francis Russo, Elements de bibliographie de l'histoire des sciences et des techniques (Paris: Hermann, 1969).

Eugene S. Ferguson, Bibliography of the History of Technology (Cambridge, Mass.:

The Society for the History of Technology and MIT Press, I968).

20 For example, Dr. Melvyn Usselman, a historian of chemistry at the University of Western Ontario, provided advice concerning the chemistry category; Professor George Richardson, a historian of mining and technology at Queen's University, Kingston, recommended revisions that were incorporated into the structure of the mining category; and Dr. Norman Ball, a historian of technology, also provided advice on the classification of technology.

2I The works consulted at this stage of the development of the subject scheme included:

Eric Arthur and Thomas Ritchie, Iron: Cast and Wrought Iron in Canada from the Seventeenth Century to the Present (Toronto: University of Toronto Press, I982).

Canadian Society of Civil Engineers, Index of Transactions Vols. I-XXIV [1887-1910] (Montreal: Printed for the Society at The Witness Press, I9I I).

Canadian Subject Headings (Ottawa: National Library of Canada, 1978).

Fred H. Colvin and K.A. Juthe, The Working of Steel Annealing, Heat Treating and Hardening of Carbon and Alloy Steel, 2d ed. (New York: McGraw Hill Book Company, I922).

T.K. Derry and Trevor I. Williams, A Short History of Technology from Earliest Times to A.D. 1900 (London: Oxford University Press, I960; reprint ed., 1973).

William H. Doolittle, Inventions in the Century (Toronto: The Linscott Publishing Company, 1902).

D.B. Dowling, comp., General Index to the Reports of Progress 1863 to 1884 lof the Geological Survey of Canada] (Ottawa: Printed by S.E. Dawson, Printer to the Queen's Most Excellent Majesty, I900).

A. Rupert Hall, The Revolution in Science 1500-1750 (New York: Longman, I983). Egon Larsen, A History of Invention (London: J.M. Dent \& Sons, I969). 
D.M. LeBourdais, Metals and Men. The Story of Canadian Mining (Toronto: McClelland \& Stewart, I957).

H.E. MacDermot, A Bibliography of Canadian Medical Periodicals with Annotations (Montreal: Renouf Publishing Co., 1934).

Manufacture of Cement, Manufacture of Paper, Manufacture of Sugar, Petroleum and Products, Manufacture of Gas (Scranton: International Textbook Company, 1902).

McGraw-Hill Encyclopedia of Science and Technology, 3d ed. (New York: McGrawHill Book Company, I971).

R.P. Multhauf, The Origins of Chemistry (New York: Franklin Watts, I966).

W. George Richardson, A Survey of Canadian Mining History (N.p.: The Canadian Institute of Mining and Metallurgy, I974).

Tracy I. Storer and Robert L. Usinger, General Zoology, 4th ed. (New York: McGraw-Hill Book Company, I 965).

Carl L. Wilson and Walter E. Loomis, Botany, 4th ed. (New York: Holt, Rinehart and Winston, 1967).

Morris Zaslow, Reading the Rocks. The Story of the Geological Survey of Canada 1842-1972 (Toronto: The Macmillan Company of Canada Limited, I975).

22 J.W. Lubbock, Remarks on the Classification of the Different Branches of Human Knowledge (London: C. Knight, I839), p. 2. Quoted in Ia McIlwaine, John Mcllwaine, and Peter G. New, eds., Bibliography and Reading. A Festschrift in Honour of Ronald Staveley (Metuchen, N.J.: The Scarecrow Press, I983), p. II9.

23 There have been a number of studies on the specialization of science in the nineteenth century. Included among these is William Coleman, Biology in the Nineteenth Century: Problems of Form, Function and Transformation (New York: John Wiley \& Sons, I97I); Stephen F. Mason, A History of the Sciences (New York: Collier-Macmillan, I962), chapters 33-4I; and a more recent paper on this topic, Dick Stemerding, 'The Construction of Biology as a Modern Science in the r9th century,' in Werner Callebaut, et al., eds., George Sarton Centennial (Ghent, Belgium: Communication \& Cognition, I984), pp. 94-96.

24 See E. Gordon Young, The Development of Biochemistry in Canada (Toronto: University of Toronto Press, 1976).

25 D.J. Foskett has written that 'we have to arrange the known so that it facilitates the discovery of the unknown.' D.J. Foskett, Library Classification and the Field of Knowledge (London: Chaucer House, I958), p. I4.

26 In his forthcoming book, Technology in Canadian History, Professor George Richardson will treat the topic in three time periods - up to I850, I850-1900, and I900-I940: personal communication.

27 Charles A. Cutter, Rules for a Dictionary Catalog, 4th ed. (Washington: U.s. Government Printing Office, I904), rule 175, p. 72.

28 B.C. Vickery, Classification and Indexing in Science (London: Butterworths, 1975), Appendix A, pp. I47-80. See also the interesting paper on early multilingual and multiscript indexes by Hans $\mathrm{H}$. Wellisch, 'Early Multilingual and Multiscript Indexes in Herbals,' The Indexer I I, no. 2 (I978): 81-102.

29 Vickery, Classification and Indexing, p. I 47.

30 See W. Boyd Rayward, 'The Search for Subject Access to The Catalogue of Scientific Papers 1800-1900,' In W. Boyd Rayward, ed., The Variety of Librarianship. Essays in Honour of John Wallace Metcalfe (Sydney: Library Association of Australia, 1976), pp. I 46-70.

3I See for example, Daryl E. Chubin, 'The Conceptualization of Scientific Specialities,' 
The Sociological Quarterly I7 (1976), [448]-76.

32 Soergel, Indexing Languages, p. I 3.

33 Francis Miksa, The Subject in the Dictionary Catalog from Cutter to the Present (Chicago: American Library Association, 1983), p. 7.

34 Robinson, Systematic Bibliography, p. 4I.

35 Roy Stokes has commented that 'although the bibliographer may sometimes receive suggestions from the perusal of a published scheme, it is unwise to adopt a ready made scheme uncritically.' Stokes, Function of Bibliography, p. Io4. 
APPENDIX A Subject Classification-Sample of Outline

Scientific topics

$50^{1}$ Botany

51 Lower Plants (Algae, Fungi, Lichens, Mosses)

53 Forestry

54 Higher Plants (Pteridophytes, Spermatophytes)

56 Materia Medica

58 Plant Classification

59 Physiological Botany (including Morphology)

60 Conservation and Environment

$\cdot$

$\cdot$

130 Geology

131 Geodesy

132 Geophysics and Physical Geology

133 Mineralogy, Economic Geology, Crystallography

134 Palaeontology

136 Palaeobotany

137 Palaeozoology

139 Stratigraphy

1 Note: the numbers represent keys assigned to each descriptor in the Outline of Subject Categories. The numbers are used for efficient sorting of the computer files and will be replaced by the actual subject descriptors in the final Bibliography.

APPENDIX в Subject Classification-Sample of Outline

Technological topics

300 Agriculture

-

370 Materials and Processes

371 Ceramics

372 Chemical Industry

373 Explosives

$374 \quad$ Photography

$376 \quad$ Fuels

377 Lumber Industry and Woodworking

378 Mills, Factories, and Foundaries

380 Mining

381

382

383

384

385

386

388

Underground Operations and Surface Mining Milling/Crushing Smelting/Refining Mills

Metallurgy

Metalworking

Paper Making and Printing

Textiles 
APPENDIX C Sample-Inverted Index to the Subject Classification

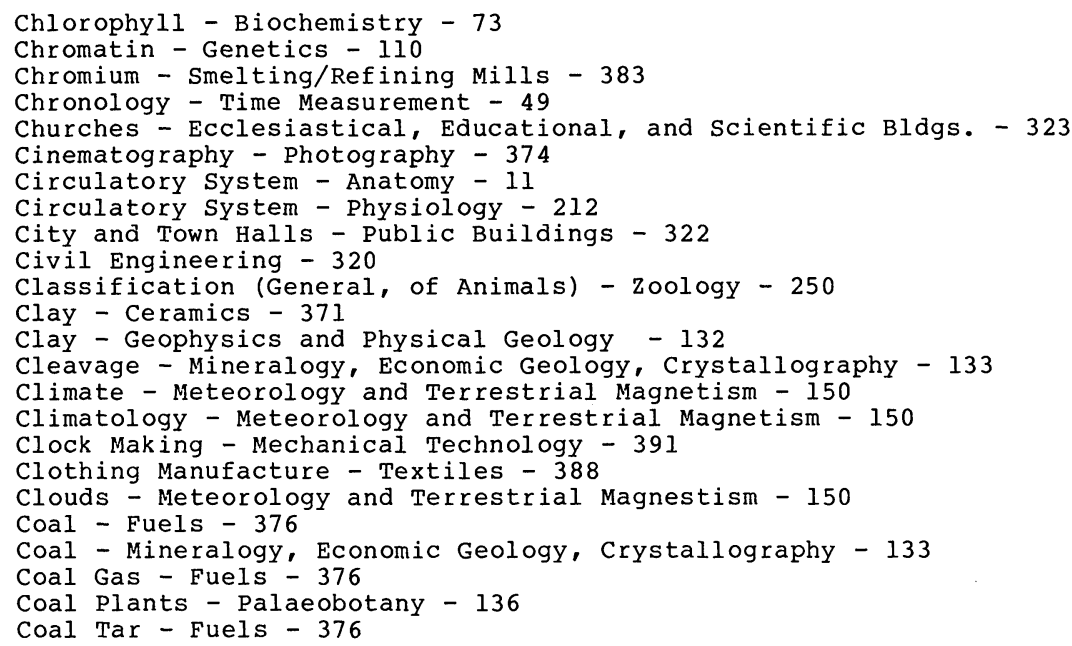

APPENDIX D Sample Thesaurus

130 GEOLOGY

132 GEOPHYSICS AND PHYSICAL GEOLOGY

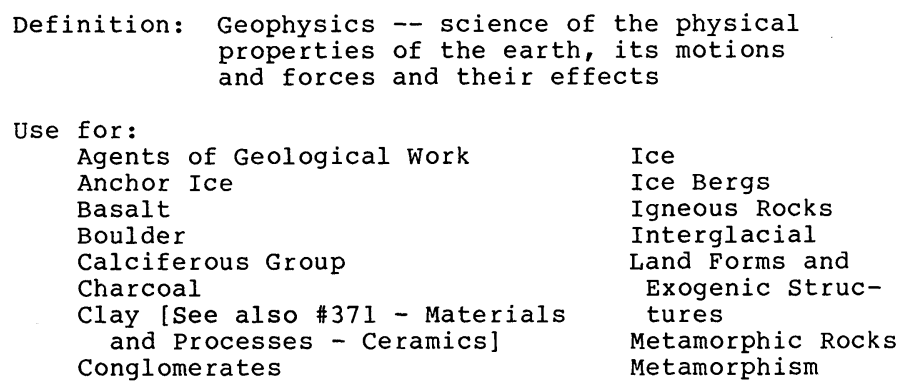


APPENDIX E Sample Thesaurus

50 BOTANY

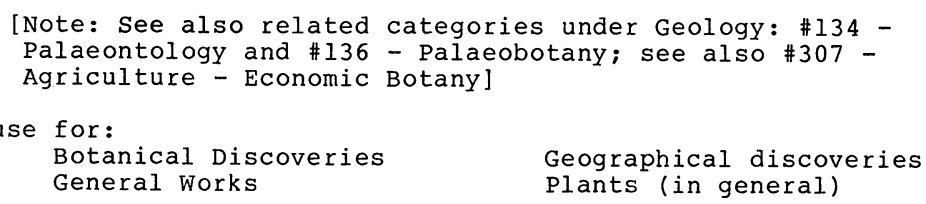

51 LOWER PLANTS (ALGAE/FUNGI/LICHENS/MOSSES)

[Note: See also related categories \#175 - oceanography and \#176 - Study of Inland Waters (including

Limnology) ]

use for:

$\begin{array}{ll}\text { Bryophyta } & \text { Sporulation } \\ \text { Cryptogamia } & \text { Sporophyte } \\ \text { Mycology } & \text { Spore } \\ \text { Protophyta } & \end{array}$

340 ENERGY

-

$\cdot$

349

ELECTRICITY

[Note: This category is reserved for technological

applications of electricity. For theoretical and scientific treatments see related category \#202 - physics Electricity and Magnetism]

POWER GENERATION, STORAGE, AND TRANSMISSION

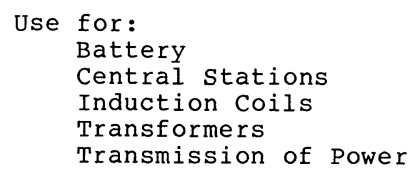

